\title{
Comparison of Caudal Epidural Steroid Injection with Interlaminar Lumbar Epidural Injection in treating Spinal Stenosis
}

\author{
MUHAMMAD AKRAM ${ }^{1}$, FAHEEM MUBASHIR FAROOQI ${ }^{2}$, TAUSEEF AHMAD BALUCH ${ }^{3}$, SHUMAILA JABBAR ${ }^{4}$ \\ ${ }^{1}$ Assistant Professor of Orthopedic Surgery and Traumatology, KEMU/Mayo Hospital Lahore \\ ${ }^{2}$ Senior Registrar, Department of Orthopedic Surgery and Traumatology, KEMU/Mayo Hospital Lahore \\ ${ }^{3} A P M O$, Department of Orthopedic Surgery and Traumatology, KEMU/Mayo Hospital Lahore \\ ${ }^{4}$ Pathologist, Qarshi University Lahore \\ Correspondence to Dr. Muhammad Akram, Email: akramaz@gmail.com, Contact:03334264350
}

\begin{abstract}
Background: Lumbar spinal stenosis is a condition caused by narrowing of spinal canal. Steroid injection either lumbar or caudal can improve the functional outcome and low back pain.

Aim: To compare the outcome of caudal epidural steroid injection with lumbar epidural steroid injection in treating spinal stenosis in patients suffering from sciatica.

Methods: In this prospective study 338 patients having low backache due to spinal stenosis with sciatica were included from June 2013 to December 2014. Patients were randomly divided into two groups. Group I and II. Patients in Group I (160 patients) received caudal epidural steroid injections while the patients in Group II (178 patients) received lumbar epidural steroid injections. Visual analog scale (VAS) and Oswestry Disability Index (ODI) was used to assess outcome of the Caudal and Lumbar steroid injections and was measured at 2 weeks, at 3months, and improvement was declared if VAS decrease $\geq 50 \%$ of baseline and Oswestry disability index decrease $\geq 40 \%$ at 3 months.

Results: In group I, there were 70(43.75\%) males and 90(56.25\%) females, while in group II there were $98(55.1 \%)$ males and $80(44.9 \%)$ females. The mean age of the patients in group I was $46.46 \pm 10.37$ (18-75 years) years and was $43.77 \pm 15.27$ years (18-75 years) in group II $(\mathrm{P}=0.0619)$. The change in pain score $(>50 \%)$ was observed in $159(89.33 \%)$ in group II compared with $121(75 \%)$ in group I ( $\mathrm{P}=0.0008)$.

Conclusion: Lumbar epidural of steroids injections are more effective then caudal epidural injection of steroids in treating spinal stenosis.

MeSH words: Caudal epidural, Lumbar epidural, Sciatica
\end{abstract}

\section{INTRODUCTION}

The most important cause of disability in the world is low backache, ${ }^{(1)}$ and one of the most important causes of low back pain is lumbar spinal stenosis ${ }^{2}$. Surgery is considered to be the gold standard modality in managing the patient with symptomatic spinal stenosis ${ }^{2}$. Considering the significant risk and great expense associated with surgery, a multitude of new technologies have been developed including minimally invasive lumbar decompression and interventional techniques such as epidural injections and percutaneous adhesiolysis 3,4 .

In a survey, epidural steroid injections were considered to be the first line invasive treatments after conservative management failed to provide significant relief to pain in patients and were referred for surgical interventions ${ }^{5}$.

Epidural injections in lumbar spine are administrated by three ways i.e. caudal epidural, lumbar transforaminal and lumbar interlaminar. Usually epidural injections are administered after the conservative management fails, the conservative management includes, NSAIDs, exercise, physical therapy, relaxants and other analgesics. A randomized trial comparing transforaminal epidural with interlaminar epidural showed that bilateral transforaminal epidural are superior to interlaminar epidural but transforaminal epidural are associated with high risks and are not practical ${ }^{6}$

Received on 27-03-2021

Accepted on 25-08-2021
Radcliff et al in 2013 in his study showed that there is high rate of use of epidural steroid injection despite, conflicting reports regarding the efficacy of epidural injection in randomized controlled trials and a lack of cost effectiveness. However, their subgroup analysis provided inappropriate conclusion because of improper inclusion of literature and a poorly designed retrospective analysis and large difference in sample sizes ${ }^{3}$.

Manchikant et al conducted two studies in 2012 and 2015 in which he compared caudal and interlaminar epidural in lumbar central spinal stenosis with 2 years follow up showed $54 \%$ improvement in caudal epidural compared with $84 \%$ in interlaminar lumbar epidural ${ }^{7,8}$.

The aim of the study was to assess the outcome and to compare both caudal and interlaminar epidural injections of steroids in lumbar central spinal stenosis.

Hypothesis: The hypothesis was that interlaminar lumbar epidural injections are superior to caudal epidural injections of steroids in pain relief and radiculopathy in lumbar central stenosis.

\section{MATERIAL AND METHODS}

This randomized, prospective comparative study was conducted in Unit I of the Department of Orthopedic Surgery and Traumatology, Mayo Hospital Lahore, from June 2013 to December 2014 after taking consent from ethical review board.

Patients having lumbar spinal stenosis (confirmed on MRI lumbosacral spine) with pain in lower limb for more than 6 months and conservative treatment failed to relieve 
pain were included in this study. An informed written consent was taken from each patient. Patients with foraminal stenosis, having history of previous spine surgery, diabetic neuropathy, paraesthesia due to other medical disorders and having medical disorders were excluded from the study

A sample size of 338 cases fulfilling the inclusion criteria were calculated with $95 \%$ confidence level, $7 \%$ margin of error and taking expected percentage of efficacy i.e. $75 \%$ with administration of epidural corticosteroids for management of sciatica. The patients were divided randomly (using lottery method) into two groups, In Group I each patient received caudal epidural injection of $120 \mathrm{mg}$ of methylprednisolone acetate in combination with $3-5 \mathrm{ml}$ of $2 \%$ plain lignocaine and $10-20 \mathrm{ml}$ of normal saline while Group II received interlaminar lumbar epidural injections of $120 \mathrm{mg}$ of methylprednisolone acetate in combination with $3-5 \mathrm{ml}$ of $2 \%$ plain lignocaine and $10-20 \mathrm{ml}$ of normal saline.

The procedure took place in the operation theatre and after the assessment of vitals and maintaining the intravenous line the patients in group I were positioned in prone with the sacral area draped. Under aseptic measure sacral hiatus was palpated and a wide bore lumbar puncture (LP) needle of $20 \mathrm{G}$ inserted at 45 degrees into the sacral hiatus and it was confirmed by pushing the air in the needle and auscultating at sacral region. Once it was confirmed that the LP needle was at right place then $3-5 \mathrm{ml}$ of inj. $2 \%$ lignocaine was injected followed by $120 \mathrm{mg}$ of methyl prednisolone acetate then $10-20 \mathrm{ml}$ of normal saline was injected. Patient was then kept in recovery room for 1 hour and then was discharged. While the patients in group II were given interlaminar lumbar epidural injection of steroids after the assessment of vitals. L2-3 intervertebral space was marked under image intensifier and then using epidural set no. $18 \mathrm{G}$ the needle was inserted and patient was given the steroid of same dose as in patients of group I.

Patients were assessed at 2 weeks and 3 months. Visual analog score was used to assess the pain in which zero means no pain while 10 mean unbearable pain. Oswestry Disability Index (ODI) was also assessed and it represents the disability as follows ${ }^{25}$ :
$0 \%-20 \% \rightarrow$ minimal disability

$20 \%-40 \% \rightarrow$ moderate disability

$40 \%-60 \% \rightarrow$ severe disability

$60 \%-80 \% \rightarrow$ crippled backache

$80 \%-100 \% \rightarrow$ bedbound or exaggerating their symptoms ${ }^{25}$. Improvement was labeled if pain decreased $\geq 50 \%$ of baseline and Oswestry disability index increased $\geq 40 \%$ at 3 months of follow up.

\section{RESULTS}

There were $70(43.75 \%)$ males and $90(56.25 \%)$ females in group I while in group II there were $98(55.1 \%)$ males and $80(44.9 \%)$ females The mean age of the patients in group I was $46.46 \pm 10.37$ (18-75 years) years and was $43.77 \pm 15.27$ years (18-75 years) in group II $(P=0.0619)$. No significant difference was present among the groups in demographic variables (table I).

The mean pain as measured on Visual Analogue Scale (VAS) was 6.48 \pm 0.67 (ranged 5.00 and 8.00 ) in group II while was $7.36 \pm 1.37$ (ranged 5.00 and 8.00 ) in group I before starting the injection $(p=0.3)$. At two weeks follow-up the VAS was $3.97 \pm 1.32$ in group II compared with group I which was $4.96 \pm 0.97(P<0.0001)$. At final followup at 3 months in group II the change in pain score (>50\%) was observed in 159 patients (89.33\%) compared with 121 patients $(75 \%)$ in group I $(P=0.0008)$. The VAS at final follow-up was $2.10 \pm 0.87$ in group II while it was $3.12 \pm 0.91$ in group I $(\mathrm{P}<0.0001)$ (table II).

The average Oswestry index in patients before starting the injections was $47.71 \pm 11.12$ (ranged $30-76$ ) in group II while it was $48.08 \pm 11.32$ in group I( $P=0.7622)$. At two weeks the ODI in group II was $20.6 \pm 6.4$ compared with group I which was $24.3 \pm 7.4(\mathrm{P}<0.0001)$. At final follow-up the mean Oswestry score in group II was $13.52 \pm 6.71$ while it was $15.15 \pm 7.69$ in group I $(P=0.0382)$. The change in Oswestry index (>40\%) was observed in 157(88.21\%) in group II compared to $113(70.62 \%)(p<0.0001)$ (Table III). No major complications seen in both group. None of the patients of either group developed any neurological deficit after the injection.

Table I: Demographic and clinical data of patients.

\begin{tabular}{|l|l|l|l|}
\hline & Group I & Group II & P Value \\
\hline Mean Age & $46.46 \pm 10.37$ & $43.77 \pm 15.27$ & $=0.0619$ \\
\hline Gender (male/Female) & $70 / 90$ & $98 / 80$ & $<0.05$ \\
\hline Mean VAS (Pre-injection) & $7.36 \pm 1.37$ & $6.48 \pm 0.67$ & $=0.3$ \\
\hline Mean ODI (Pre-injection) & $48.08 \pm 11.32$ & $47.71 \pm 11.12$ & $=0.762$ \\
\hline
\end{tabular}

Table II: Comparison of Caudal and Lumbar epiduralresults basedVAS

\begin{tabular}{|l|l|l|l|l|}
\hline Outcome Measure & Time & Group I & Group II & P value \\
\hline \multirow{3}{*}{ Mean VAS leg Pain } & Preinjection & $7.36 \pm 1.37$ & $6.48 \pm 0.67$ & $=0.3$ \\
\cline { 2 - 5 } & 2 weeks post injection & $4.96 \pm 0.97$ & $3.97 \pm 1.32$ & $<0.0001$ \\
\cline { 2 - 5 } & 3 months post injection & $3.12 \pm 0.91$ & $2.10 \pm 0.87$ & $<0.0001$ \\
\hline Overall Patients & & $121(75 \%)$ & $159(89.33 \%)$ & $<0.0008$ \\
\hline
\end{tabular}

Table III: Comparison of Caudal and Lumbar epidural results based Disability

\begin{tabular}{|l|l|l|l|l|}
\hline Outcome Measure & Time & Group I & Group II & P value \\
\hline \multirow{3}{*}{ Mean ODI } & Preinjection & $48.08 \pm 11.32$ & $47.71 \pm 11.12$ & $=0.762$ \\
\cline { 2 - 5 } & 2 weeks post injection & $24.3 \pm 7.4$ & $20.6 \pm 6.4$ & $<0.0001$ \\
\cline { 2 - 5 } & 3 months post injection & $15.15 \pm 7.96$ & $13.5 \pm 6.71$ & $=0.0382$ \\
\hline Overall Patients & & $113(70.62 \%)$ & $157(88.21 \%)$ & $<0.0001$ \\
\hline
\end{tabular}




\section{DISSCUSSION}

This randomized controlled trail of injecting steroid for managing lumbar spinal stenosis either by caudal approach or by lumbar translaminar approach showed the efficacy of both approach at the end of 3 months. However, the lumbar translaminar approach was superior to caudal epidural at 3 months. $89.33 \%$ patients of group II showed more than $50 \%$ decrease in VAS while only $75 \%$ patients of group I showed improvement at 3 months after the procedure. As both these procedures were performed to provide relief to patients with persistent and chronic low backache, both showed significant improvement in the patients with spinal stenosis. However, the patients who showed no response with the procedure were higher in caudal epidural than the lumber epidural $(24.37 \%$ in caudal epidural and $10.67 \%$ in lumbar epidural). There was no difference in outcome based on level of stenosis and severity.

The caudal epidural injections may be limited with spread of the drug above the level of S1 in some patients. L4/L5 involvement was $90 \%$ in a study by Radcliff et al in $2013^{3}$. So it appears that sometimes the drug does not reach to the level of pathology in caudal epidural so interlaminar lumbar epidural injection is more effective as it provides drug close to the pathology.

Multiple studies support the efficacy of lumbar interlaminar epidural injection in managing the lumbar spinal stenosis ${ }^{9,10,11}$ whereas Friedly et al in 2014 in a study contradicted the outcome of lumbar epidural in treating lumbar spinal stenosis with moderate to severe leg pain ${ }^{12}$. But later in 2014 Anderson criticized the study of Friedly et al, for their design, the mode of outcome assessment, quality of literature review, performance of procedures with variable volumes of drug injected and conclusion that there is a lack of efficacy though the results clearly show that both Transforaminal and Interlaminar approaches were effective with Interlaminar approach showing superior results $^{12,13}$. Bresnahan et al and Ammendolia et al also being criticized for their poor search criteria and inappropriate analysis leading to conclusion based on no evidence ${ }^{14,15}$. However, the systemic reviews utilizing appropriate methodology showed moderate efficacy in managing the central spinal stenosis ${ }^{4}$. So still there has not been any study published in which there is comparative analysis performed in single study though there is study published in 2014 showing comparison of two studies ${ }^{16}$.

\section{CONCLUSION}

We conclude that both caudal epidural steroid injections and translaminar lumbar epidural steroids injections provide adequate pain relief and functional improvement in spinal stenosis with sciatica however translaminar lumbar epidural injection of steroids yields better pain relief and functional improvement than caudal epidural injection of steroids.

Acknowledgment: We thank our seniors who allowed us to conduct this study.
Conflict of interest: No conflict of interest to declare. Contribution of authors: MA: Primary Surgeon Co supervisor, FMH: Assistant Surgeon and Statistical and data analyzer, SJ: Statistical and data analyzer

\section{REFERENCE}

1. Murray CJ, Atkinson C, Bhalla K. The state of US health, 19902010: burden of diseases, injuries, and risk factors. JAMA 2013; 310(6):591-608.

2. Zaina F, Tomkins-Lane C, Carragee E, Negrini S. Surgical versus non-surgical treatment for lumbar spinal stenosis. Cochrane Database of Systematic Reviews. 2016(1)

3. Radcliff K, Kepler C, Hilibrand A. Epidural steroid injections are associated with less improvement in patients with lumbar spinal stenosis: a subgroup analysis of the Spine Patient Outcomes Research Trial. Spine (Phila Pa 1976) 2013;38(4):279-291.

4. Manchikanti L, Abdi S, Atluri S, Benyamin RM, Boswell MV, Buenaventura RM, Bryce DA, Burks PA, Caraway DL, Calodney AK, Cash KA. An update of comprehensive evidence-based guidelines for interventional techniques in chronic spinal pain. Part II: guidance and recommendations. Pain physician. 2013 Apr;16(2 Suppl):S49-283.

5. Lebude B, Wang D, Harrop JS, Maltenfort M, Anderson DG, Vaccaro AR, Ratliff JK. Clinical survey: Patterns of utilization of lumbar epidural steroid injections by a cohort of spinal surgeons. PM R 2009; 1:329-334.

6. Atluri S, Glaser SE, Shah RV, Sudarsha G. Needle position analysis in cases of paralysis from transforaminal epidurals: Consider alternative approaches to traditional techniques. Pain Physician 2013; 16:321-334.

7. Manchikanti L, Cash KA, McManus CD,Pampati V, Fellows B. Results of 2-yearfollow-up of a randomized, doubleblind, controlled trial of fluoroscopiccaudal epidural injections in centralspinal stenosis. Pain Physician 2012; 15:371-384.

8. Manchikanti L, Cash KA, McManus CD,Damron KS, Pampati V, Falco FJE. A randomized,double-blind controlled trialof lumbar interlaminar epidural injectionsin central spinal stenosis: 2-year follow-up. Pain Physician 2015; 18:79-92.

9. Fairbank JC, Pynsent PB. The Oswestry Disability Index. Spine 2000 Nov 15;25(22):2940-52; discussion 52

10. Wilson-MacDonald J, Burt G, Griffin D, Glynn C. Epidural steroid injection for nerve root compression: $A$ randomized, controlled trial. J Bone Joint Surg Br 2005; 87-B:352-355.

11. Koc Z, Ozcakir S, Sivrioglu K, Gurbet A, Kucukoglu S. Effectiveness of physical therapy and epidural steroid injections in lumbar spinal stenosis. Spine (Phila Pa 1976) 2009; 34:985-989

12. Friedly JL, Comstock BA, Turner JA, Heagerty PJ, Deyo RA, Sullivan SD, Bauer Z, Bresnahan BW, Avins AL, Nedeljkovic SS, Nerenz DR. A randomized trial of epidural glucocorticoid injections for spinal stenosis. New England Journal of Medicine. 2014 Jul 3;371(1):11-21.

13. Anderson GB. Epidural glucocorticoidinjections in patients with lumbar spinalstenosis. N Engl J Med 2014; 371:75-76.

14. Ammendolia C, Stuber K, de Bruin LK, Furlan AD, Kennedy CA, Rampersaud YR, Steenstra IA, Pennick V. Nonoperative treatment of lumbar spinal stenosis with neurogenic claudication: a systematic review. Spine (Phila Pa 1976) 2012; 37:E609-E616.

15. Bresnahan BW, Rundell SD, Dagadakis MC, Sullivan SD, Jarvik JG, Nguyen H, Friedly JL. A systematic review to assess comparative effectiveness studies in epidural steroid injections for lumbar spinal stenosis and to estimate reimbursement amounts. PM R 2013; 5:705-714.

16. Manchikanti L, Falco FJ, Pampati V, Hirsch JA. Lumbar interlaminar epidural injections are superior to caudal epidural injections in managing lumbar central spinal stenosis. Pain Physician. 2014 Nov 1;17(6):E691-702. 